Revista de Negócios_ISSN 1980.4431_vol. 18, n.3, p.37_57, 2013_DOI:10.7867/1980-

431.2013v18n3p37_57

\title{
Análise conjunta do ciclo de vida e da longevidade empresarial: um enfoque em indústria, comércio e agronegócio
}

\section{Joint analisys life cycle and longevity business: a focus on industry, commerce and agribusiness}

\author{
Ricardo William Pinheiro \\ FNH Faculdade Novos Horizontes - Brasil \\ ricardo.pinheiro@mestrado.unihorizontes.br \\ Wendel Alex Castro Silva \\ FNH Faculdade Novos Horizontes - Brasil \\ wendel.silva@unihorizontes.br \\ Elisson Alberto Tavares Araújo \\ FNH Faculdade Novos Horizontes - Brasil \\ elisson.araujo@unihorizontes.br
}

*Os autores agradecem o apoio da Fapemig

Recebido em 6 de novembro de 2012. Alterado em 5 de fevereiro de 2013. Aprovado em 9 de fevereiro de 2013

Editor Responsável: Edson Roberto Scharf, Dr.

Processo de avaliação por double blind review

\section{Resumo}

$\mathrm{O}$ estudo do ciclo de vida das organizações (CVO) torna-se relevante para que as empresas saibam em qual fase situam-se, podendo, desse modo, dimensionar melhor suas estratégias em busca de uma maior longevidade. Assim, este artigo tem como objetivo principal identificar em qual fase do CVO situam-se as empresas industriais, comerciais e do agronegócio de Patrocínio/MG, com base na perspectiva teórica de Adizes (1990). Busca-se também identificar quais as práticas de gestão das empresas longevas - enunciadas por Martins e Pereira (2009), essas empresas têm adotado. Nesse sentido, realizou-se uma pesquisa descritiva e quantitativa, obtendo-se uma amostra de 38 empresas. No levantamento dos dados, aplicou-se questionário fechado, baseado em Adizes, com escala Likert de cinco pontos, os quais foram analisados por meio da técnica de Ranking Médio (RM) para verificar o nível de concordância entre os respondentes. Pôde-se constatar que, a maior parte das empresas situa-se nas fases de plenitude e estabilidade, e poucas nas fases de infância e adolescência. Provavelmente, estão em uma transição para o período de envelhecimento, como sinaliza a abordagem de Adizes (1990). Naquelas mais longevas essa fase de transição foi percebida em uma intensidade menor. E, essas empresas sinalizaram estar adotando quase todas as práticas de gestão, como preconizado pela teoria. Concluiu- 
Análise conjunta do ciclo de vida e da longevidade empresarial: um enfoque em indústria, comércio e agronegócio

se que as empresas com até 5 anos parece estarem na fase de transição para o período de envelhecimento e ainda não adotam algumas práticas das empresas longevas, bem como a seleção e implementação de estratégias adequadas, o que demanda maior atenção de seus gestores quanto à isso, sob pena de prejudicar sua consolidação, e reduzir seu ciclo de vida.

Palavras-chave: Ciclo de Vida Organizacional, longevidade, empresas.

\begin{abstract}
The study of the organizational life cycle (OLC) becomes important for companies to know what phase are located and, therefore, their strengths and weaknesses, allowing better prepare to achieve longevity. We aimed to identify in what stage of the OLC situate the industrial, commercial and agribusiness of Patrocínio/MG, based on the theoretical perspective of Adizes (1990), and what management practices of longevous enterprises, listed by Martins and Pereira (2009), these enterprises have adopted. Accordingly, there was a descriptive and quantitative, getting a sample of 38 enterprises. In the survey data, we had applied closed questionnaire, based on Adizes, with fivepoint Likert scale, which were analyzed by the technique of Rank Medium (MR) to check the level of agreement among respondents. It was noted that most enterprises lies in the stages of fullness and stability, and few phases of childhood and adolescence. Possibly have been in a transition to the aging period, as signals theory Adizes (1990). Those longer-lived this phase transition was perceived in a lower intensity. And these enterprises have signaled be adopting almost all management practices, as suggested by theory. We conclude that, enterprises with up to 5 years, seem to come in a phase of transition to the aging period and still do not adopt some practices of lived enterprises, demanding more attention from their managers regarding it, otherwise impair its consolidation and reduce their longevity.
\end{abstract}

Keywords: Organizational Life Cycle, longevity, enterprises.

\section{Introdução}

As empresas do mundo global, cada vez mais competitivo, se submetem a uma série de adaptações que altera o seu ambiente interno. Em longo prazo, esse movimento provoca mudanças no ambiente externo em que estão inseridas. Especificamente, se tornam mais competitivas no que diz respeito a custo, a qualidade e a variedade, ao buscarem inovação em alguma dessas áreas (MAUAD, MARTINELLI; LIBONI, 2005; JUNQUEIRA et al., 2008). Já, em relação ao processo de sobrevivência, notase que, assim como os seres vivos, elas nascem, crescem, morrem ou renovam, o que remete a um ciclo de vida marcado por diferentes estágios, que para Adizes (1990), seguem padrões previsíveis e podem ser caracterizados por estágios de desenvolvimento (MAUAD, MARTINELLI; LIBONI, 2005).

Tentando descrever esse fenômeno, vários pesquisadores tem se dedicado ao tema ciclo de vida nas organizações (CVO) e muitos deles propuseram modelos teóricos. Greiner (1972) foi o precursor dessa temática e elaborou estudos que o levaram a formular um modelo dividido em cinco estágios, quais sejam: criatividade, centralização, delegação, coordenação e equipe. Churchill e Lewis (1983) também sugeriram um modelo com cinco estágios, mas direcionado para a caracterização de pequenas empresas. Mintzberg (1984) propôs um modelo com apenas quatro estágios segmentados em formação, desenvolvimento, maturidade e declínio. Scott e Bruce (1987) apresentaram um modelo que condicionava as fases da empresa à capacidade do proprietário de conseguir equilibrar as necessidades com as disponibilidades. Já Adizes (1990) criou um modelo mais completo, em nove fases, com fulcro no ciclo de vida do homem, sendo: namoro (courtship), infância (infant), toca-toca (go-go), adolescência (adolescence), plenitude ou apogeu (prime), estabilidade (maturity), aristocracia (aristocracy), burocracia incipiente (nascent bureaucracy) e burocracia (bureaucracy).

Entender o CVO é importante, pois subsidiará os gestores na busca pela sustentabilidade organizacional, a fim de atingir a longevidade, o que ainda é difícil de alcançar segundo a pesquisa que apurou uma taxa de mortalidade de $49,4 \%$, no Brasil, em 2002 (SEBRAE, 2004). Ainda, apenas uma pequena parcela das micro e 
pequenas empresas (MPE's) em operação, ultrapassam os primeiros quatro anos de funcionamento (DIEESE, 2008). Martins e Pereira (2009) afirmam que as organizações somente conseguem se manter vivas no cenário atual caso contribuírem para o setor em que estão inseridas, sendo assim, uma organização que alcance a longevidade contribuirá para sua sobrevivência, mas, também, para a longevidade do setor, movimentando a economia, gerando empregos e renda.

$\mathrm{Na}$ última década, vários estudos no Brasil abordaram a questão do CVO, dentre os quais destacam-se: Freitas et al. (2002) examinaram o CVO de empresas supermercadistas; Lucena (2003) investigou a administração estratégica nas fases do CVO; Andrade et al. (2004) analisaram a relação entre o CVO e as estratégias de MPE's; Battilana e Beraldo (2004) analisaram o CVO de uma empresa do varejo; Mauad e Martinelli (2005) apresentaram uma proposta de CVO para a administração pública; Frohlich, Rosseto e Silva (2007) estudaram as práticas de gestão no CVO; Junqueira et al. (2008) desenvolveram um modelo de CVO; Castro Silva, Jesus e Melo (2010) examinaram o CVO de MPE's industriais de Contagem/MG e; Oliveira et al. (2012) estudaram o CVO de escritórios de contabilidade. Já dentre os estudos sobre longevidade, Dutra e Previdelli (2005) identificaram elementos determinantes da mortalidade de MPE's do Paraná; Ferreira (2001) estudou os fatores que influenciam na longevidade de empresas moveleiras de Curitiba; Martins e Pereira (2009) analisaram a longevidade de empresas têxteis de Santa Catarina e; Oliveira, Castro Silva e Araújo (2012) investigaram a longevidade e as características empreendedoras de MPE's de Teófilo Otoni/MG. Assim, não foram obtidos trabalhos atuais que tivessem abordado o $\mathrm{CVO} \mathrm{e}$ as práticas de gestão de empresas agrocomerciais e agroindustriais, no Brasil, fundamentando-se na perspectiva teórica de CVO de Adizes (1990). Torna-se relevante estudar essas empresas na medida em que são responsáveis por boa parte da produção de riqueza do município de Patrocínio, no Estado de Minas Gerais. Além do mais, a geração de informações sobre as mesmas poderá contribuir à gestão de empresas de segmento semelhantes aos analisados. Cabe salientar ainda que, quanto maior a longevidade dessas empresas, maior será a perspectiva de desenvolvimento nesse mercado.

Nesse cenário, a questão-problema que orienta este estudo é a seguinte: em que fase do CVO situam-se as empresas industriais, comerciais e do agronegócio de Patrocínio/MG, a partir da teoria de Adizes (1990), e quais as práticas de gestão das empresas longevas, enunciadas por Martins e Pereira (2009), elas têm adotado?

Portanto, o objetivo central desse estudo é identificar em que fase do CVO situam-se as empresas industriais, comerciais e do agronegócio de Patrocínio/MG, com base na perspectiva teórica de Adizes (1990), e quais as práticas de gestão das empresas longevas, enunciadas por Martins e Pereira (2009), essas empresas têm adotado.

Serão analisadas empresas que fazem parte da Associação Comercial e Industrial de Patrocínio/MG (ACIP), organização que abrange a maioria do empresariado patrocinense.

Depois desta seção introdutória, na próxima seção é construída a revisão de literatura; na seção três apresenta-se a metodologia da pesquisa empírica; na quarta seção são apresentados e discutidos os resultados; na última seção são tecidas as considerações finais e a conclusão.

\section{Revisão de literatura}

\subsection{Ciclo de Vida das Organizações}

O uso de metáforas é comum nos estudos organizacionais, dentre as quais, é relevante para o estudo de CVO aquela que 
Análise conjunta do ciclo de vida e da longevidade empresarial: um enfoque em indústria, comércio e agronegócio

trata as empresas como organismos complexos, sistemas abertos que interagem com o meio ambiente para sobreviver e se desenvolver. Esses estudos assemelham-se aos estudos biológicos quando se comparam as relações entre moléculas, células, organismos complexos, espécies e ecologias, com as relações que abrangem indivíduos, grupos, organizações, populações de organizações e sua ecologia social. Tal semelhança permitiu estabelecer estudos fundamentados na evolução biológica, gerando o que se denominou de CVO, que analisa o crescimento e o desenvolvimento das empresas durante sua existência (MORGAN, 1996; FREITAS, COSTA; BARROSO, 2002).

As abordagens propostas pelos estudos de CVO apresentam também grande relação ao Darwinismo e propõem uma reflexão sobre a luta pela sobrevivência das empresas, em geral portadoras de variações ou características adaptativas às condições ambientais, que no longo prazo trazem vantagens competitivas sobre aquelas empresas que não as possuem. Assim, a adaptação traz crescimento de mercado por meio de diferenciação, devido à capacidade de inovação necessárias às variações adaptativas.

A partir desse enfoque biológico, o conceito de ciclo de vida pode ser aplicado ao estudo do crescimento e desenvolvimento de mercado, sobre o ciclo de vida tecnológico dos setores industriais, comerciais e de serviços, com ênfase nas áreas de economia; além da administração e do marketing quando se analisa o ciclo de vida do produto e/ou da empresa (MAUAD, MARTINELLI e LIBONI, 2005).

Ao analisar o CVO espera-se compreender todo o processo de mudança sofrido pelas empresas ao longo de sua trajetória, atentando-se aos detalhes e às mudanças que ocorreram. O objetivo é averiguar como uma empresa evoluiu, como se comportou ao longo do tempo, e ainda, investigar cada fator e sua influência nesse trajeto (MACHADO-DA-SILVA,
VIEIRA, DELLAGNELO, 1998; LUCENA, 2003).

As empresas são sistemas abertos que interagem com o ambiente, sofrendo influências dele no seu crescimento sob alguns aspectos, tais como, na estrutura funcional, nas estratégias, na percepção em relação às oportunidades e ameaças, e no modo como a empresa irá se comportar em relação às mesmas. Assim, só se pode compreender o desenvolvimento e os fatores que geram sucesso e fracasso, ao decorrer do tempo, por meio da análise conjunta, empresa e ambiente (MILLER; FRIESEN, 1984; BATTILANA; BERALDO, 2004).

Durante sua trajetória, a empresa analisa o ambiente em que estão inseridas e procuram adaptar-se a ele; nesse processo natural de evolução, amplia-se a complexidade do ambiente e das tarefas administrativas na medida em que vão atingindo etapas com características peculiares que variam desde a fase de inovação (i.e. criação, surgimento), crescimento, até as fases mais conservadoras de estagnação e envelhecimento (MILLER e FRIESEN, 1984; ANDRADE, et al., 2004).

Todavia, diferente dos seres vivos, algumas empresas podem renovar e recomeçar todo o seu ciclo de desenvolvimento. As fases do ciclo organizacional podem ocorrer de maneira não linear, e uma empresa pode retornar ao início do CVO sem chegar à morte. Todos os sistemas abertos tendem a experimentar a morte, porém, a empresa pode utilizar sua capacidade de manter-se viva entropia negativa - para combater essa tendência e reiniciar o ciclo (KATZ e KAHN, 1976).

Cada fase do CVO é marcada por uma série de disfunções que a empresa terá que enfrentar para se tornar longeva. Muitos estudos buscaram identificar e compreender as características de cada fase, alguns com base na estrutura organizacional, outras, no conhecimento dos administradores e, ainda, analisando 
elementos do meio ambiente da organização, mas, todos, visando entender essas fases e identificar os fatores geradores do sucesso e da longevidade empresarial (QUINN; CAMERON, 1983).

\subsection{Longevidade Empresarial}

Longevidade empresarial trata-se do sucesso atingido por uma empresa com a sua existência continuada, podendo chegar a centenas de anos, com eficiência e forte desempenho (FLECK, 2005; MAYFIELD, MAYFIELD; STEPHENS, 2007). É o período em que uma organização ou empresa mantém-se ativa, o que depende, dentre várias suposições, de sua persistência ou vontade de seus administradores, eficiência dos recursos e capacidade de renovação. Longevidade pode ser também caracterizada como capacidade de ir além das probabilidades de sobrevivência em um mercado qualquer ou economia.

Diversos estudos buscaram analisar os elementos que influenciam no sucesso e no fracasso das organizações. Para Dutra e Previdelli (2005), esses estudos devem-se à ascensão de empresas que selecionaram uma gestão dinâmica, obtendo sucesso, e pelo declínio daquelas que adotam a gestão tradicionalista. No entanto, tal fato contrapõe a suposição que não exista melhor maneira de organizar, sobreponto à ideia de que a forma adequada depende das circunstâncias do ambiente e dos aspectos estruturais, tais como o conteúdo das atividades inerentes a uma determinada empresa.

Por outro lado, a busca pelo sucesso empresarial passaria pela compreensão e o domínio de técnicas que levam à produtividade organizacional com qualidade, e desempenho superior àquele dos concorrentes. Sendo assim, são vários os pesquisadores da área administrativa que consideram a eficiência e eficácia nos negócios importantes elementos, para se obter êxito e garantir um longo período de atividades (DUTRA; PREVIDELLI,
2005).

Mas, se por um lado, ainda existe dúvidas quanto as abordagens que analisam o caminho para o sucesso e o fracasso organizacional. A partir da análise de CVO pode ser segregadas, basicamente, variáveis entre aquelas que atribuem maior importância às características do indivíduo, frente à organização; e aquelas que consideram os fatores contextuais como sendo os mais destacados.

Dentre os que atribuem maior importância às características dos indivíduos, fatores como, pouca experiência do gestor, falta de conhecimento e habilidades administrativas, mercadológicas, tecnológicas e financeiras podem levar ao fracasso empresarial. Por outro lado, um empreendedor deve buscar uma visão transparente do mercado em que opera, além de um elevado nível de conhecimento e domínio de atividades que são peculiares ao seu negócio para conseguir obter o êxito (DEGEN, 1989; DOLABELA, 1999; FERREIRA, 2001). Para alguns pesquisadores os fatores sociais, econômicos, tecnológicos e políticos, i.e., os originados das circunstâncias ambientais são as causas do surgimento, do crescimento e do sucesso empresarial (CALDAS, FACHIN; FISCHER, 1998; FERREIRA, 2001).

É possível também englobar essas duas abordagens quando se analisa as dinâmicas estratégicas implantadas pelas empresas como as bases para atingir a longevidade, pelo fato de serem considerados os aspectos do ambiente interno - e do externo, na gestão das empresas. Partindo desse ponto pode-se afirmar que o estudo das escolhas estratégicas promove um melhor entendimento sobre sua longevidade quando relacionado às práticas de gestão das empresas (BURGELMAN; GROVE, 2007).

Pode-se salientar que a dinâmica do CVO está atrelada ao modelo gerencial que se desenvolve ao dos anos. Nesse aspecto, Martins e Pereira (2009) relacionaram os principais estudos sobre longevidade 
Análise conjunta do ciclo de vida e da longevidade empresarial: um enfoque em indústria, comércio e agronegócio

empresarial e as práticas de gestão (vide Quadro 1).

\begin{tabular}{|c|c|c|c|c|c|c|c|c|c|}
\hline \multirow{2}{*}{ Práticas De Gestão } & \multicolumn{5}{|c|}{ Estudos Internacionais } & \multicolumn{4}{|c|}{ Estudos No Brasil } \\
\hline & $\mathbf{I} *$ & II* & III* & IV* & $\mathbf{V}^{*}$ & VI* & VII* & VIII* & IX* \\
\hline Aprendizado de Melhorias Constantes & & $\mathrm{x}$ & $\mathrm{X}$ & $\mathrm{x}$ & & & & & \\
\hline Conhecimento do Mercado & $\mathrm{x}$ & $\mathrm{x}$ & & $\mathrm{x}$ & $\mathrm{x}$ & $\mathrm{x}$ & $\mathrm{x}$ & $\mathrm{x}$ & $\mathrm{x}$ \\
\hline Controle Financeiro & $\mathrm{x}$ & $\mathrm{x}$ & & & & & $\mathrm{x}$ & & $\mathrm{x}$ \\
\hline Coordenação Administrativa & $\mathrm{x}$ & & & & & & $\mathrm{x}$ & & $\mathrm{x}$ \\
\hline Crescimento Não Planejado & & & $\mathrm{x}$ & & & & & & \\
\hline Cultura Arraigada & & $\mathrm{x}$ & $\mathrm{x}$ & $\mathrm{x}$ & $\mathrm{x}$ & $\mathrm{x}$ & & & \\
\hline Estratégia Transparente E Definida & & & & & $\mathrm{x}$ & $\mathrm{x}$ & $\mathrm{x}$ & & $\mathrm{x}$ \\
\hline Estrutura Complexa & & & & & & & & & \\
\hline Estrutura Flexível & & & & & $\mathrm{x}$ & & & $\mathrm{x}$ & \\
\hline Foco Na Tecnologia & & & & $\mathrm{x}$ & & & $\mathrm{x}$ & & \\
\hline Foco No Crescimento E Desempenho Planejado & $\mathrm{x}$ & & & $\mathrm{X}$ & $\mathrm{x}$ & & & & \\
\hline Hierarquia Gerencial & $\mathrm{x}$ & & & & & & & & \\
\hline Inovação Constante & $\mathrm{x}$ & $\mathrm{x}$ & $\mathrm{x}$ & & $\mathrm{x}$ & & $\mathrm{x}$ & $\mathrm{x}$ & $\mathrm{x}$ \\
\hline Investimentos & $\mathrm{X}$ & & & & & & & & \\
\hline Liderança & $\mathrm{x}$ & & & $\mathrm{X}$ & $\mathrm{x}$ & $\mathrm{x}$ & $\mathrm{x}$ & $\mathrm{x}$ & $\mathrm{x}$ \\
\hline Metas Explícitas & $\mathrm{X}$ & & $\mathrm{x}$ & $\mathrm{x}$ & $\mathrm{x}$ & & & & \\
\hline Parcerias & $\mathrm{X}$ & & & & $\mathrm{x}$ & & & & \\
\hline Processo Decisório Descentralizado & & $\mathrm{x}$ & & & & & & & \\
\hline Processo Sucessório & $\mathrm{x}$ & $\mathrm{x}$ & $\mathrm{x}$ & & $\mathrm{x}$ & & & $\mathrm{x}$ & \\
\hline Senso De Comunidade & & $\mathrm{x}$ & & & & & & & \\
\hline Senso De Identidade & $\mathrm{x}$ & $\mathrm{x}$ & $\mathrm{x}$ & $\mathrm{x}$ & & & & & \\
\hline Valorização Das Pessoas & & $\mathrm{x}$ & $\mathrm{x}$ & $\mathrm{x}$ & $\mathrm{x}$ & & & $\mathrm{x}$ & \\
\hline
\end{tabular}

*Legenda: I) Autoperpetuação; II) Empresa Viva; III) Empresa Visionária; IV) Empresa Grandiosa; V) Empresa

Vencedora; VI) Empresa de Sucesso; VII) MPE Brasileira; VIII) Empresa Duradoura; IX) MPE Catarinense.

Quadro1: Comparativo dos Estudos Sobre Longevidade Empresarial

Fonte: Martins e Pereira, 2009.

A partir do quadro anterior, foi gestão utilizadas pelas empresas longevas, elaborado um ranking das práticas de elencado na Tabela 1.

Tabela 1: Ranking das Práticas de Gestão Utilizadas por empresas longevas

\begin{tabular}{|c|c|c|}
\hline Ordem & Prática de Gestão & Total \\
\hline $1^{\circ}$ & Conhecimento do mercado & 8 \\
\hline $2^{\circ}$ & Liderança & 7 \\
\hline $2^{\circ}$ & Inovação constante & 7 \\
\hline $3^{\circ}$ & Valorização das pessoas & 5 \\
\hline $3^{\circ}$ & Processo sucessório & 5 \\
\hline $3^{\circ}$ & Senso de identidade & 5 \\
\hline $3^{\circ}$ & Cultura arraigada & 5 \\
\hline $4^{\circ}$ & Controle financeiro & 4 \\
\hline $4^{\circ}$ & Estratégia transparente e definida & 4 \\
\hline $4^{\circ}$ & Metas transparentes & 4 \\
\hline $4^{\circ}$ & Foco na tecnologia & 4 \\
\hline $5^{\circ}$ & Coordenação administrativa & 3 \\
\hline $5^{\circ}$ & Foco no crescimento e desempenho & 3 \\
\hline $5^{\circ}$ & Aprendizado e melhoria constantes & 3 \\
\hline $6^{\circ}$ & Estrutura flexível & 2 \\
\hline $6^{\circ}$ & Parcerias & 2 \\
\hline $6^{\circ}$ & Processo decisório & 2 \\
\hline $7^{\circ}$ & Estrutura complexa & 1 \\
\hline $7^{\circ}$ & Crescimento não planejado & 1 \\
\hline $7^{\circ}$ & Hierarquia gerencial & 1 \\
\hline $7^{\circ}$ & Investimentos & 1 \\
\hline $7^{\circ}$ & Senso de comunidade & 1 \\
\hline
\end{tabular}


Fonte: Martins e Pereira, 2009.

As características apresentadas na Tabela 1 não esclarecem por completo o perfil de gestão de um empreendedor que busca a longevidade de seu negócio. As características relacionadas principalmente às questões culturais, regionais devem complementar o que foi apresentado. No entanto, é possível determinar alguns aspectos em comuns nesses estudos, como o conhecimento de mercado, a existência de uma estratégia inovadora, a preocupação com as pessoas dentro da organização, a liderança exercida de maneira firme, mas sem arrogância, e a existência de objetivos transparentes e bem definidos (MARTINS; PEREIRA, 2009).

O controle financeiro também tem demonstrado, por vários estudos, imprescindível à longevidade empresarial sobretudo em mercados onde o fluxo da demanda sofrem mudanças abruptas devido à estrutura da industrial, a concorrência e o gosto dos consumidores. Assim, quanto maior o planejamento de caixa maior previsibilidade frente às incertezas; maior será o sucesso no planejamento de longo prazo, por conseguinte, maior a expectativa de longevidade da empresa. Mas, outro ponto importante, e menos discutido, está relacionado às ênfases que são dadas a cada etapa de vida, desse modo, os modelos mentais de planejamento, criação, crescimento, conservadorismo e renovação resultam diferentes comportamentos e práticas de gerenciamento. Da mesma maneira, os objetivos e as aspirações de permanecer no mercado ou não, o desejo de crescer, mudar ou desaparecer - de uma empresa dependem dos modelos mentais vigentes, que são amplamente relacionados às forças existentes em cada etapa de seu desenvolvimento.

\subsection{Fases do CVO na Perspectiva de Adizes (1990)}

Apesar de ciclo de vida e longevidade da empresa serem temas separados, na prática, a longevidade está fortemente relacionada à gestão das etapas do CVO. Desse modo, dentre os modelos de CVO existentes, nesta pesquisa, optouse pela aplicação da tipologia de Adizes (1990), na qual são comparados os estágios da trajetória empresarial àquelas da trajetória humana, fazendo-se evidentemente uma apologia às teorias evolucionárias quando se que medir os modelos mentais que conduzem as empresas em todo o seu desenvolvimento.

Assim, segundo Adizes (1992) as empresas passam por três períodos no decorrer de sua vida, quais sejam: i) crescimento composto pelas fases de namoro (courtship), infância (infant) e toca-toca (go-go); ii) maioridade, que abarca as fases de adolescência . (adolescence) e plenitude (prime) e; iii) envelhecimento que inclui as fases de estabilidade (maturity), aristocracia (aristocracy), burocracia incipiente (nascent bureaucracy) e burocracia (bureaucracy).

Em cada uma dessas fases as empresas apresentam características que refletem períodos de desenvolvimento (i.e. atributos relacionados a cada fase) ou de dificuldades que perpassam durante toda uma existência. Apesar de o modelo de Adizes ser um dos mais completos, permitindo a transição ao longo das etapas de vida, ele não diz nada sobre a capacidade de renovação das empresas. Para ele a etapa final, e menos desejável, é a burocracia. Diferente do modelo de Greiner que considera a renovação como um importante mecanismo de mudança, para Adizes as empresas se paralisam e começam a endossar por um longo período de tempo os mesmos produtos, serviços e estruturas. Neste ponto, elas atingiram seu estágio de envelhecimento.

Apresenta-se no Quadro 2 um resumo das características da organização 
Análise conjunta do ciclo de vida e da longevidade empresarial: um enfoque em indústria, comércio e agronegócio

em cada fase do CVO de Adizes (1990).

\begin{tabular}{|c|c|c|c|c|c|c|c|c|}
\hline \multicolumn{9}{|c|}{ Ciclo de Vida Organizacional } \\
\hline & \multicolumn{2}{|c|}{ Período de Crescimento } & \multicolumn{2}{|c|}{ Período de Maioridade } & \multicolumn{4}{|c|}{ Período de Envelhecimento } \\
\hline Fases & Infância & Toca-Toca & Adolescência & Plenitude & Estabilidade & Aristocracia & $\begin{array}{l}\text { Burocracia } \\
\text { Incipiente }\end{array}$ & $\begin{array}{c}\text { Burocracia e } \\
\text { Morte }\end{array}$ \\
\hline$I^{*}$ & - & - & $\begin{array}{l}\text { Surgimento de } \\
\text { hierarquia }\end{array}$ & Bem definida & $\begin{array}{c}\text { Perda de } \\
\text { flexibilidade }\end{array}$ & $\begin{array}{c}\text { Grande } \\
\text { formalidade }\end{array}$ & - & $\begin{array}{l}\text { Se mantém } \\
\text { viva por } \\
\text { interesses } \\
\text { políticos }\end{array}$ \\
\hline II* & $\begin{array}{c}\text { Grande } \\
\text { necessidade } \\
\text { de capital } \\
\text { operacional }\end{array}$ & $\begin{array}{c}\text { Maior } \\
\text { consistência de } \\
\text { caixa }\end{array}$ & - & - & Conforto & - & - & $\begin{array}{c}\text { Faltam } \\
\text { recursos } \\
\text { financeiros }\end{array}$ \\
\hline III* & Grande & - & $\begin{array}{c}\text { Descentralização } \\
\text { vulnerável }\end{array}$ & - & - & - & - & - \\
\hline $\mathrm{IV} *$ & $\begin{array}{c}\text { Dificuldade } \\
\text { em conseguir } \\
\text { sua satisfação }\end{array}$ & Fiéis & - & $\begin{array}{l}\text { São mais bem } \\
\text { conhecidos }\end{array}$ & - & Diminuição & $\begin{array}{l}\text { Torna-se um } \\
\text { aborrecimento }\end{array}$ & $\begin{array}{c}\text { Falta de } \\
\text { compromisso } \\
\text { com o cliente }\end{array}$ \\
\hline $\mathrm{V}^{*}$ & - & Comprometidos & - & $\begin{array}{l}\text { São mais bem } \\
\text { conhecidos }\end{array}$ & - & - & - & - \\
\hline VI* & - & $\begin{array}{c}\text { Falta controle na } \\
\text { institucionalização }\end{array}$ & - & - & Conforto & - & $\begin{array}{c}\text { Muitas brigas } \\
\text { e conflitos }\end{array}$ & - \\
\hline VII* & - & Falta & - & Resultados & $\begin{array}{c}\text { Preocupação } \\
\text { decrescente } \\
\text { com o futuro }\end{array}$ & - & - & $\begin{array}{c}\text { Básicos e } \\
\text { visando a } \\
\text { sobrevivência } \\
\text { da } \\
\text { organização }\end{array}$ \\
\hline VIII* & - & - & $\begin{array}{l}\text { Quebra do } \\
\text { processo }\end{array}$ & Institucionalizadas & & $\begin{array}{c}\text { Menores } \\
\text { investimentos }\end{array}$ & - & - \\
\hline $\mathrm{IX}^{*}$ & $\begin{array}{c}\text { Busca pela } \\
\text { sobrevivência }\end{array}$ & - & - & $\begin{array}{l}\text { Revelação de } \\
\text { estratégias que } \\
\text { garantam a } \\
\text { rentabilidade } \\
\text { futura }\end{array}$ & $\begin{array}{l}\text { Assumem-se } \\
\text { menos riscos }\end{array}$ & $\begin{array}{c}\text { A empresa se } \\
\text { torna } \\
\text { previsível }\end{array}$ & - & - \\
\hline $\mathrm{X}^{*}$ & $\begin{array}{l}\text { Poucas ou } \\
\text { nenhuma }\end{array}$ & - & $\begin{array}{c}\text { São } \\
\text { incorporadas }\end{array}$ & - & - & - & - & - \\
\hline $\mathrm{XI}^{*}$ & - & Inexistente & - & Existente & - & - & - & - \\
\hline XII* & - & - & - & Bem definidos & $\begin{array}{c}\text { Maior } \\
\text { interesse nas } \\
\text { relações } \\
\text { interpessoais }\end{array}$ & $\begin{array}{c}\text { Maiores } \\
\text { investimentos }\end{array}$ & - & $\begin{array}{l}\text { Numerosos, } \\
\text { complexos e } \\
\text { com pouca } \\
\text { funcionalidade }\end{array}$ \\
\hline XIII* & - & $\begin{array}{c}\text { Aumentando e } \\
\text { sem planejamento }\end{array}$ & - & $\begin{array}{c}\text { Supera a } \\
\text { expectativa de } \\
\text { desempenho e } \\
\text { mantém } \\
\text { crescimento nas } \\
\text { vendas } \\
\end{array}$ & $\begin{array}{l}\text { Expectativas } \\
\text { menores de } \\
\text { crescimento }\end{array}$ & - & - & - \\
\hline XIV* & $\begin{array}{c}\text { Essenciais } \\
\text { para } \\
\text { sobrevivência } \\
\text { da empresa }\end{array}$ & Entusiasmados & $\begin{array}{c}\text { Acreditam que } \\
\text { devem se ligar a } \\
\text { questões } \\
\text { externas }\end{array}$ & Confiantes & - & - & - & - \\
\hline $\mathrm{XV}^{*}$ & - & $\begin{array}{c}\text { Grande } \\
\text { conhecimento e } \\
\text { boa estrutura }\end{array}$ & - & - & Conforto & - & - & - \\
\hline
\end{tabular}

*Legenda: I) Estrutura organizacional; II) Aspectos financeiros; III) Centralização; IV) Clientes; V) Fornecedores; IV) Pessoas; VII) Objetivos; VIII) Inovação e criatividade; IX) Estratégia; X) Regras e procedimentos; XI) Planejamento; XII) Sistemas; XIII) Vendas; XIV) Fundadores; XV) Processo produtivo.

Quadro 2: Características em cada fase do CVO.

Fonte: Elaborado pelos autores com base em Adizes, 1990.

\subsection{Trabalhos Recentes sobre CVO e/ou Longevidade}

Nessa seção forma obtidos alguns trabalhos recentes que investigaram a temática da longevidade empresarial e/ou CVO, sendo apresentadas no Quadro 3.

\begin{tabular}{|c|l|l|}
\hline \multicolumn{2}{|c|}{ Objetivo } & \multicolumn{1}{c|}{ Considerações/Conclusões } \\
\hline \multicolumn{3}{|c|}{ Internacionais } \\
\hline Liao & $\begin{array}{l}\text { Associar vantagem competitiva, análise } \\
\text { de custos de transação e o modelo de }\end{array}$ & $\begin{array}{l}\text { Conforme o CVO que a organização estiver é } \\
\text { necessário um incentivo estratégico para obter } \\
(2008)\end{array}$ \\
& CVO para analisar um sistema de & $\begin{array}{l}\text { vantagens diferentes, sendo, muitas vezes, um } \\
\text { mix entre eles. }\end{array}$ \\
\hline Engelen, Brettel & Comparar os antecedentes e os efeitos & O estágio do CVO exerce influência moderadora \\
e Heinemann & da orientação de marketing (OM) na & nas relações entre OM e seus antecedentes, \\
\hline
\end{tabular}




\begin{tabular}{|c|c|c|}
\hline$(2010)$ & ganização, nos estágios do CVO. & cerca do desempenho. \\
\hline $\begin{array}{l}\text { Dibrel, Craig e } \\
\text { Hansen } \\
\text { (2011) }\end{array}$ & $\begin{array}{l}\text { Estudar os efeitos do ambiente natural e } \\
\text { da fase do CVO sobre a orientação para } \\
\text { o mercado de firmas com inovações em } \\
\text { relacionamento. }\end{array}$ & $\begin{array}{l}\text { As organizações que estão no início do CVO são } \\
\text { mais propensas a ter uma política ambiental } \\
\text { positiva para o meio ambiente gerando uma } \\
\text { vantagem competitiva por meio de inovação. }\end{array}$ \\
\hline $\begin{array}{l}\text { Dickinson } \\
\text { (2011) }\end{array}$ & $\begin{array}{l}\text { Desenvolver uma proxy de CVO } \\
\text { utilizando-se de fluxos de caixa padrão. }\end{array}$ & $\begin{array}{l}\text { Essa proxy mostrou-se robusta, pois incorpora } \\
\text { distintos comportamentos da firma no CVO. }\end{array}$ \\
\hline $\begin{array}{l}\text { Madhani } \\
(2012)\end{array}$ & \begin{tabular}{|l} 
Explicar o impacto do CVO no \\
desempenho e a resposta do gerente de \\
recursos humanos na gestão de \\
compensação em MPE's da Índia.
\end{tabular} & $\begin{array}{l}\text { O reequilíbrio da remuneração fixa e variável, } \\
\text { conforme a fase do CVO, ajuda as organizações } \\
\text { na elaboração de estratégias de remuneração para } \\
\text { obtenção de vantagem competitiva. }\end{array}$ \\
\hline \multicolumn{3}{|c|}{ Nacionais } \\
\hline $\begin{array}{l}\text { Frohlich, Rosseto } \\
\text { e Silva (2007) }\end{array}$ & $\begin{array}{l}\text { Analisar a influência das práticas de } \\
\text { gestão nos estágios de CVO em uma } \\
\text { organização de médio porte. }\end{array}$ & $\begin{array}{l}\text { A alteração das práticas de gestão, num modelo } \\
\text { de gestão estruturado, pode influenciar no CVO, } \\
\text { evitando o seu declínio ou a morte. }\end{array}$ \\
\hline $\begin{array}{l}\text { Souza, Necyk e } \\
\text { Frezzati } \\
(2008)\end{array}$ & 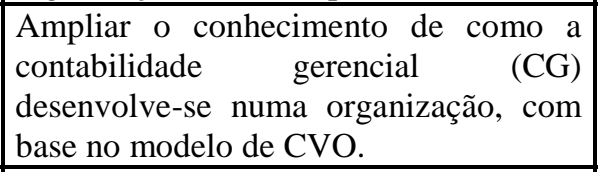 & $\begin{array}{l}\text { Os estudos empíricos comprovam que as } \\
\text { características da CG são influenciadas pelos } \\
\text { estágios do CVO. }\end{array}$ \\
\hline $\begin{array}{l}\text { Junqueira et al. } \\
\qquad(2008)\end{array}$ & \begin{tabular}{|l|l|} 
Apresentar uma abordagem \\
epistemológica do estado da arte das \\
pesquisas sobre o CVO.
\end{tabular} & $\begin{array}{l}\text { se que o tema não está devidamente } \\
\text { ido. }\end{array}$ \\
\hline $\begin{array}{l}\text { Martins e Pereira } \\
\text { (2009) }\end{array}$ & $\begin{array}{|lccr|}\text { Identificar } & \text { se } & \text { as empresas longevas } \\
\text { utilizaram no seu CVO alguma das } \\
\text { práticas de gestão atinentes à } \\
\text { longevidade organizacional. }\end{array}$ & stão, \\
\hline $\begin{array}{l}\text { Carvalho et al. } \\
\qquad(2010)\end{array}$ & $\begin{array}{l}\text { Realizar uma análise teórica das } \\
\text { contribuições das teorias do CVO sobre } \\
\text { a pesquisa em CG. }\end{array}$ & $\begin{array}{l}\text { na de CG varia conforme elementos } \\
\text { acionais internos e externos da empresa } \\
\text { se nas diferentes fases do CVO. }\end{array}$ \\
\hline $\begin{array}{r}\text { Castro } \\
\text { Jesus e } \\
\quad(20 \\
\end{array}$ & $\begin{array}{l}\text { Identificar em qual estágio do CVO } \\
\text { estão algumas MPE's industriais de } \\
\text { Contagem, a partir de Adizes (1990). } \\
\end{array}$ & $\begin{array}{l}\text { As empresas apresentam características que } \\
\text { contribuíram para sua longevidade, mas mantêm } \\
\text { outras que podem levá-las à mortalidade. }\end{array}$ \\
\hline $\begin{array}{l}\text { Costa e Dias } \\
\quad(2011)\end{array}$ & $\begin{array}{l}\text { Identificar o papel da "mentoria" em } \\
\text { empresas familiares e se contribui para a } \\
\text { longevidade empresarial. }\end{array}$ & $\begin{array}{l}\text { A mentoria sempre esteve presente, informal e } \\
\text { positivamente na vida profissional e pessoal dos } \\
\text { entrevistados, contribuindo para a longevidade. }\end{array}$ \\
\hline $\begin{array}{l}\text { Beuren, Rangel e } \\
\text { Hein } \\
(2012)\end{array}$ & $\begin{array}{l}\text { Identificar os estágios do CVO, } \\
\text { pautados no modelo de Lester, Parnell e } \\
\text { Carraher (2003), de indústrias de } \\
\text { máquinas, aparelhos e materiais } \\
\text { elétricos de Santa Catarina. }\end{array}$ & $\begin{array}{l}\text { Alguns estágios estão próximos uns dos outros e } \\
\text { não se percebeu uma progressão determinista nas } \\
\text { suas fases, enquanto sequência única, definitiva e } \\
\text { irreversível, biologicamente. }\end{array}$ \\
\hline $\begin{array}{l}\text { Oliveira et al. } \\
\quad(2012)\end{array}$ & \begin{tabular}{|l|} 
Averiguar o nível de aderência entre a \\
estrutura funcional de escritórios \\
contábeis e o estágio do CVO, segundo \\
a teoria de Miller e Friesen (1984). \\
\end{tabular} & $\begin{array}{l}\text { orte relação entre os fatores } \\
\text { l e o CVO das empresas. }\end{array}$ \\
\hline $\begin{array}{l}\text { Oliveira, Castro } \\
\text { Silva e Araújo } \\
\quad(2012)\end{array}$ & $\begin{array}{l}\text { Identificar a relação entre a longevidade } \\
\text { de MPE's da microrregião de Teófilo } \\
\text { Otoni/MG, e as características } \\
\text { comportamentais atribuídas aos } \\
\text { empreendedores de sucesso. }\end{array}$ & $\begin{array}{l}\text { A presença das características empreendedoras } \\
\text { mostrou-se conectada à longevidade dos } \\
\text { empreendimentos. }\end{array}$ \\
\hline
\end{tabular}

Quadro 3: Pesquisas recentes no mercado internacional e no doméstico

Fonte: Compilado pelos autores.

Dentre as pesquisas identificadas na academia, tanto nacional quanto estrangeira, percebe-se maior frequência de estudos sobre CVO, e alguns diretamente relacionados às MPE's. Entretanto, as práticas gerenciais adequadas mostram-se relevantes para a manutenção e crescimento das organizações, auxiliando no seu aprimoramento e em sua longevidade. 
Análise conjunta do ciclo de vida e da longevidade empresarial: um enfoque em indústria, comércio e agronegócio

Particularmente no mercado interno, sinaliza-se ser incipiente o interesse dos pesquisadores acerca do tema longevidade em MPE's.

Não há ainda, um corpo sólido sobre o tema que permita a formação de uma abordagem mais consistente dentro de um arcabouço teórico devido à dispersão de interesses, e até mesmo, a questão do empreendedorismo tem pouco enfoque nesses estudos, sendo apenas interesse de uns dos achados. Essa é uma questão complexa e impossível de ser resolvida em uma única pesquisa. No entanto, a expectativa é preencher um pouco essa lacuna conforme proposta apresentada na seção de metodologia, logo a seguir.

\section{Metodologia}

Esta pesquisa possui natureza empírico-descritiva, visto que busca descrever o comportamento dos fenômenos e não analisar suas causas (COLLIS e HUSSEY, 2005). Desse modo, procura-se identificar em que fase do CVO situam-se as empresas industriais, comerciais e do agronegócio de Patrocínio/MG, com base na perspectiva teórica de Adizes (1990), além disso, averigua quais as práticas de gestão das empresas longevas, - conforme enunciadas por Martins e Pereira (2009) essas empresas têm adotado.

Possui caráter de objetividade, em que se visa a mensuração de fenômenos, por intermédio da coleta e análise de dados numéricos, com a aplicação de testes estatísticos (COLLIS; HUSSEY, 2005). As unidades de análise foram as MPE's do município de Patrocínio/MG, e seus proprietários e/ou gestores constituíram as unidades de observação. Como o mecanismo de obtenção de dados foi um questionário estruturado, é do tipo survey (HAIR Jr. et al., 2009).

A amostra foi retirada de uma população de 720 empresas associadas à ACIP de Patrocínio, na região do Alto Paranaíba, no Estado de Minas Gerais, e contidas no banco de dados dessa associação, cujas áreas de atuação são empresas de indústria, comércio e do agronegócio. A amostra foi formada por 38 empresas, que responderam ao questionário, distribuídas nessas três áreas. Tratase de uma amostra constituída com base no método de amostragem não probabilístico por conveniência (disponibilidade de dados) e por julgamento (interesse do pesquisador) (HAIR Jr. et al., 2009), em que se desejou trabalhar com o maior número possível de empresas para tornar as análises generalizáveis. Partiu-se da premissa de que, o viés que decorreria da aplicação desse método tenha sido mitigado, já que se teve acesso a empresas de vários portes, setores e com perfis distintos. E de outro modo, a amostra constitui-se grande segundo o pressuposto do teorema central de limite, ou seja, amostras acima de trinta elementos.

$\mathrm{O}$ questionário, enviado por e-mail, para a obtenção dos dados sobre o CVO foi constituído por questões fechadas com respostas em Escala Likert (intervalar) de 5 pontos, à luz do raciocínio qualitativo de análises intangíveis (discordo totalmente [1] a concordo totalmente [5]) (LIKERT, 1979). Esse instrumento foi validado por Castro Silva, Jesus e Melo (2010), quando foi desenvolvido com base na teoria de Adizes (1990). Já o questionário sobre as práticas de gestão ligadas à longevidade, foi aquele validado por Martins e Pereira (2009). Ambos foram unificados em um questionário para atender aos propósitos desta pesquisa.

Esse tipo de escala não intenciona ser, "[...] mais do que uma escala ordinal [...]", que gera a ordenação de sujeitos por intermédio da favorabilidade de sua atitude acerca do objeto estudado, contudo, não fornece fundamento para se afirmar $o$ quanto um sujeito é mais favorável que outro (SELLTIZ, WRIGHTSMAN; COOK, 1987, p. 63).

O questionário, na última versão, contemplou 36 questões sobre CVO e 22 sobre longevidade, escalonados nos seguintes grupos: i) caracterização sócio- 
demográfica das empresas; ii) de análise do CVO; iii) práticas de gestão. A parte inicial teve 7 questões sobre a descrição das empresas da amostra: localização, quantidade de funcionários, setores, modelo de administração, faturamento, e outros. A parte dois - 29 questões - incluiu itens do CVO das empresas, a maturidade da administração, conhecimentos na área comercial e do negócio, escolaridade, experiência do gestor noutras empresas, capacidade de negociação, comunicação persuasiva, pensamento criativo e facilidade em solucionar problemas. A última parte, que visou identificar a presença das práticas de gestão de empresas longevas, continha 22 questões. Vez que a ferramenta já estava validada, admitiu-se que os respondentes tinham o apropriado entendimento das questões e elas repercutiam sua percepção sobre a indagação.

$\mathrm{O}$ envio dos questionários deu-se entre janeiro e março de 2011. Todos aqueles respondidos apresentaram as informações de forma completa, logo, houve inexistência de dados faltantes (missings), permitindo que a totalidade participasse das análises.

Após a aplicação do questionário, procedeu-se à análise das respostas por meio do método de Ranking Médio, o qual possibilita mensurar o grau de concordância dos sujeitos respondentes (OLIVEIRA, 2005), acerca das questões para identificação da fase do CVO e das práticas de gestão, e do seu intervalo de confiança à $95 \%$. Os resultados foram segmentados em três categorias: a média abaixo de 3 indica percepção discordante da característica da fase do CVO da empresa ou da presença da prática de gestão; a média igual a 3 denota sem opinião ou indiferença; e a média acima 3 revela concordância sobre a presença da característica na empresa. Então, avalia-se o nível de concordância quanto à fase do CVO.

$\mathrm{Na}$ obtenção dos valores, utiliza-se a média ponderada:

$\mathrm{MP}=\Sigma$ (frequências das respostas $\mathrm{x}$ escalas assinaladas) [equação 1] depois, efetua-se o cálculo do Ranking Médio:

$$
R M=\frac{M P}{\Sigma} \text { [equação 2] }
$$

Sendo:

$\mathrm{MP}=$ média ponderada;

$\Sigma=$ somatório das frequências das respostas.

Os dados obtidos foram tabulados por meio do software Microsoft Excel ${ }^{\circledR}$ versão 2007 e as análises estatísticas univariadas foram realizadas no software Statistical Package for the Social Science ${ }^{\circledR}$ (SPSS), versão 15.

\section{Apresentação e discussão dos resul- tados}

Inicialmente, dividiram-se as empresas que compuseram a amostra pelas três áreas de atuação da ACIP, o que pode ser percebido na Tabela 2 .

Tabela 2 - Divisão das empresas pela área de atuação da ACIP

\begin{tabular}{c|l|c|c|c}
\hline \multicolumn{1}{c|}{ Área } & \multicolumn{1}{c|}{ Ramo de Atividade } & Quantidade & \% & \% acumulado \\
\hline & Roupas e Calçados & 7 & 18,42 & 18,42 \\
& Combustíveis e lubrificantes & 4 & 10,53 & 28,95 \\
Comércio & Móveis e eletrodomésticos & 4 & 10,53 & 39,48 \\
& Matérias para construção & 4 & 10,53 & 50,01 \\
& Outros (supermercado, sacolão, artigos de & 9 & 23,68 & 73,69
\end{tabular}


Análise conjunta do ciclo de vida e da longevidade empresarial: um enfoque em indústria, comércio e agronegócio

$\begin{array}{lllll}\text { Indústria } & \text { Móveis e esquadrias metálicas } & 3 & 7,89 & 81,58\end{array}$

\begin{tabular}{cl|c|c|c|} 
Agronegócio & $\begin{array}{l}\text { Defensivos agrícolas, peças para tratores e } \\
\text { implementos agrícolas }\end{array}$ & 7 & \multicolumn{2}{c}{18,42} \\
\hline Total & $\mathbf{3 8}$ & $\mathbf{1 0 0 , 0}$ & \\
\hline
\end{tabular}

Fonte: Dados da pesquisa.

A despeito de ter sido constituída por conveniência, a amostra segue a tendência geral da população, ou seja, a maior parte das empresas aderentes à ACIP, conforme informação levantada pelos pesquisadores em entrevista informal com o presidente da associação é de empresas que atuam no comércio em geral; seguidas pelas empresas que atuam no agronegócio e, por último, na indústria, área com reduzida atuação em Patrocínio/MG.

De 38 empresas, $28 \quad(73,69 \%)$ dedicam-se à comercialização de produtos como roupas, calçados, artigos esportivos, móveis para residências e escritórios, equipamentos de informática, combustíveis e lubrificantes, materiais para construção, gêneros alimentícios, artigos de papelaria, entre outros; $3(7,89 \%)$ atuam na área industrial na produção de móveis e esquadrias metálicas; e $7(18,42 \%)$ estão ligadas ao agronegócio, sobremaneira, na comercialização de defensivos agrícolas e peças para tratores e implementos agrícolas.

Considerando o critério idade das empresas pode-se dividir amostra em 5 grupos conforme indica a Tabela 3 .

Tabela 3 - Divisão das empresas pela idade

\begin{tabular}{c|c|c|c}
\hline Idade da Empresa & Quantidade & \% & \% acumulado \\
\hline Até 2 anos & 4 & 10,53 & 10,53 \\
De 2 a 3 anos & 4 & 10,53 & 21,06 \\
De 3 a 5 anos & 5 & 13,16 & 34,22 \\
Acima de 5 anos & 25 & 65,78 & 100,0 \\
\hline Total & $\mathbf{3 8}$ & $\mathbf{1 0 0 , 0}$ & \\
\hline
\end{tabular}

Fonte: Dados da pesquisa.

Na Tabela 4 é possível identificar o período em que se encontram as empresas com até 2 anos. Elas têm, no máximo, 15 funcionários, faturam até $\mathrm{R} \$$ 1.200.000,00 por ano e em sua maioria são geridas pelos proprietários.

Tabela 4 - Características e Ranking Médio de Empresas com até 2 anos

\begin{tabular}{|c|c|c|}
\hline Característica & $\begin{array}{l}\text { Ranking } \\
\text { Médio }\end{array}$ & Fase do CVO \\
\hline A empresa possui diretrizes normas e regras a serem seguidas pelos funcionários & 3,50 & Adolescência \\
\hline $\begin{array}{l}\text { O enfoque principal da empresa é a produção de resultados, ou seja, a busca pelas } \\
\text { vendas }\end{array}$ & 4,00 & Plenitude \\
\hline A administração é centralizada no proprietário & 4,00 & Infância \\
\hline O ambiente é informal com poucas reuniões de pessoal e pouquíssima hierarquia & 2,75 & Plenitude \\
\hline O nível de reclamações de clientes é alto & 3,00 & Neutro \\
\hline O nível de fornecedores insatisfeitos é alto & 2,25 & Plenitude \\
\hline O nível de funcionários improdutivos é alto & 2,25 & Estabilidade \\
\hline O nível de dificuldades em obter crédito junto aos bancos é alto & 3,00 & Neutro \\
\hline A empresa não possui problemas de fluxo de caixa & 3,00 & Neutro \\
\hline O nível de vendas está aumentando rapidamente & 3,25 & Plenitude \\
\hline $\begin{array}{l}\text { A empresa não tem planejamento de vendas e assume compromissos superiores da } \\
\text { produção }\end{array}$ & 2,25 & Plenitude \\
\hline Não existem conflitos entre administradores e sócios & 4,00 & Estabilidade \\
\hline Não existem conflitos entre funcionários & 4,00 & Estabilidade \\
\hline O nível de verbas destinadas para marketing e pesquisa é alto & 3,25 & Plenitude \\
\hline Os gestores possuem os pés no chão, tem medo de mudanças & 2,25 & Plenitude \\
\hline $\begin{array}{l}\text { A empresa possui algum percentual do lucro destinado para projetos ou } \\
\text { investimentos }\end{array}$ & 2,50 & Estabilidade \\
\hline A empresa possui planejamento financeiro de curto e longo prazo com metas de & 4,00 & Plenitude \\
\hline
\end{tabular}

Revista de Negócios, ISSN 1980-4431, Blumenau, Brasil, v. 18, n. 3, p. 37-57, Julho/Setembro de 2013. 
crescimento

A motivação dos gestores e funcionários da empresa é alta 4,00 Plenitude

Fonte: Dados da pesquisa.

Apesar da administração centralizada, que conforme Adizes (1990) é uma característica da infância, foi possível identificar que essas empresas com até 2 anos possuíam várias características do período de maioridade, composto pelas fases de adolescência e plenitude. Ainda para o mesmo autor, na adolescência é que são incorporadas as regras e procedimentos que serão seguidos pelos funcionários o que pôde ser observado pela concordância entre os respondentes quando questionados se essas existiam em suas empresas.

Os respondentes foram enfáticos ao concordarem que não possuem estruturas informais e sem hierarquia, possuem um baixo nível de fornecedores e funcionários insatisfeitos e há um aumento rápido no volume de vendas. Para eles também inexistem problemas com vendas maiores que a produção, seus gestores não são conservadores, - segundo percepção, há destinação de verba para marketing e pesquisa; planejamento a curto e longo prazo e os gestores e funcionários estão motivados o que implica em empresas próxima a fase de plenitude conforme preconizado no modelo. Também, foram constatadas quatro características da fase de estabilidade, o que pode indicar uma transição dessas empresas para um período de maior amadurecimento.

Para Liao (2008), a cada fase do CVO há um tipo de custo e uma recompensa para gerar vantagem competitiva. Nas fases iniciais, esta é ampliada nas empresas que investem no meio ambiente (DIBREL; CRAIG; HANSEN, 2011), e pelas estratégias de remuneração de pessoal (MADHANI, 2012). Além disso, as ações de marketing influenciam nas fases e no desempenho (ENGELEN; BRETTEL; HEINEMANN, 2010). No entanto, é sabido que as empresas comerciais e de serviços pouco investem em meio ambiente, em comparação à indústria, além de contribuírem pouco para degradação do mesmo. No entanto, há indícios de que o cenário apresentado por essas empresas seja relacionado ao forte empenho já na profissionalização da gestão e no posicionamento de mercado. Mas, a grande preocupação sobre os resultados, foram os elementos que configuram como neutros, pois dois deles estão diretamente relacionados ao equilíbrio financeiro. Estudos sobre mortalidade de empresa têm apontado esses dois elementos como causadores do fracasso empresarial; é bastante comum encontrar empresas com dificuldades financeiras principalmente nas fases de crescimento pelo falta de gestão financeira.

$\mathrm{Na}$ Tabela 5 são apresentados os resultados das empresas de 2 à 3 anos. Elas possuem até 10 funcionários, faturam até R\$ 1.200.000,00 anuais, a metade é administrada pelo proprietário e, o restante, é gerido por este e um administrador profissional.

Assim como nas empresas com até 2 anos, há concordância entre os respondentes em relação à administração centralizada no proprietário e à existência de regras e procedimentos a serem seguidos pelos funcionários.

Tabela 5 - Características e Ranking Médio de Empresas de 2 a 3 anos

\begin{tabular}{|c|c|c|}
\hline Característica & $\begin{array}{c}\text { Ranking } \\
\text { Médio }\end{array}$ & Fase do CVO \\
\hline A empresa possui diretrizes normas e regras a serem seguidas pelos funcionários & 3,50 & Adolescência \\
\hline $\begin{array}{l}\text { O enfoque principal da empresa é a produção de resultados, ou seja, a busca pelas } \\
\text { vendas } \\
\text { A administracão é centralizada no proprietário }\end{array}$ & $\begin{array}{l}3,50 \\
3,50\end{array}$ & $\begin{array}{l}\text { Plenitude } \\
\text { Infância }\end{array}$ \\
\hline
\end{tabular}

Revista de Negócios, ISSN 1980-4431, Blumenau, Brasil, v. 18, n. 3, p. 37-57, Julho/Setembro de 2013. 
Análise conjunta do ciclo de vida e da longevidade empresarial: um enfoque em indústria, comércio e agronegócio

O ambiente é informal com poucas reuniões de pessoal e pouquíssima hierarquia

O nível de reclamações de clientes é alto

2,50

2,75

2,25

2,00

O nível de funcionários improdutivos é alto

O nível de dificuldades em obter crédito junto aos bancos é alto

A empresa não possui problemas de fluxo de caixa

O nível de vendas está aumentando rapidamente

A empresa não tem planejamento de vendas e assume compromissos superiores da produção

Não existem conflitos entre administradores e sócios

Não existem conflitos entre funcionários

O nível de verbas destinadas para marketing e pesquisa é alto

Os gestores possuem os pés no chão, tem medo de mudanças

A empresa possui algum percentual do lucro destinado para projetos ou

investimentos

A empresa possui planejamento financeiro de curto e longo prazo com metas de crescimento

A motivação dos gestores e funcionários da empresa é alta

Fonte: Dados da pesquisa.

Essas empresas de 2 à 3 anos possuem, em sua maioria, elementos de empresas que se situam no período de maioridade, na fase de plenitude. Elas estão focadas em resultados e perseguem aumento nas vendas, mas não houve concordância que falta planejamento de vendas e que não haja comprometimento do pessoal para o processo produtivo, nem que as empresas têm estruturas sem hierarquia e com poucas reuniões de pessoal, e que o nível de reclamações de clientes e fornecedores é elevado.

Por outro lado, o nível de vendas está crescendo rapidamente, as empresas destinam elevados recursos financeiros para o marketing e pesquisa, possuem planejamento financeiro de curto e longo prazo, e os gestores e funcionários têm um forte nível de motivação. Ainda, há indicativos de quatro características da fase de estabilidade, o que pode sinalizar uma transição dessas empresas para o período de envelhecimento. Nesse momento, como preconiza o modelo, as fronteiras com o ambiente são erguidas e a empresa começa lentamente a perder o contato com mesmo. As aspirações permanecem cada vez mais estáveis e, no longo prazo, o desejo de crescer e mudar começa a desaparecer.
Plenitude

Plenitude

Plenitude

Estabilidade Neutro

Estabilidade

Plenitude

Plenitude

Estabilidade

Estabilidade

Plenitude

Neutro

Neutro

Plenitude

Plenitude
Estabilidade e previsibilidade se tornam os modelos vigentes mentais. E, apesar de a contabilidade gerencial sofrer dependência de cada fase do CVO (SOUZA; NECYK; FREZZATI, 2008; CARVALHO et al., 2010) - assim com a controladoria -, passase a merecer maior a atenção dos gestores.

Aparentemente não há problemas de fluxo de caixa e não existem conflitos entre o administrador e os sócios, e entre os funcionários. Para Dickinson (2011), o fluxo de caixa é uma proxy efetiva para estudar o CVO. Discordou-se que o número de funcionários improdutivos é excessivo. No entanto, considerados questões neutras as dificuldades de crédito, a preocupação com novos investimentos e incerteza frente às mudanças.

A Tabela 6 refere-se aos resultados das empresas de 3 à 5 anos. Pode-se verificar uma divisão entre características daquelas em período de maioridade e de envelhecimento e, ainda, opiniões indiferentes acerca das características. Essas empresas têm no máximo 10 funcionários, faturam acima de $\mathrm{R} \$$ 240.000,00 anuais, e somente uma das 5 que se enquadraram nessa faixa etária é administrada pelo proprietário e um administrador profissional, o restante são administradas apenas pelo proprietário.

Tabela 6 - Características e Ranking Médio de Empresas de 3 a 5 anos

\begin{tabular}{|c|c|c|}
\hline Característica & $\begin{array}{c}\text { Ranking } \\
\text { Médio }\end{array}$ & Fase do CVO \\
\hline A empresa possui diretrizes normas e regras a serem seguidas pelos funcionários & 4,20 & Adolescência \\
\hline
\end{tabular}


vendas

A administração é centralizada no proprietário

O ambiente é informal com poucas reuniões de pessoal e pouquíssima hierarquia

O nível de reclamações de clientes é alto

O nível de fornecedores insatisfeitos é alto

O nível de funcionários improdutivos é alto

O nível de dificuldades em obter crédito junto aos bancos é alto

A empresa não possui problemas de fluxo de caixa

O nível de vendas está aumentando rapidamente

A empresa não tem planejamento de vendas e assume compromissos superiores da produção

Não existem conflitos entre administradores e sócios

Não existem conflitos entre funcionários

O nível de verbas destinadas para marketing e pesquisa é alto

Os gestores possuem os pés no chão, tem medo de mudanças

A empresa possui algum percentual do lucro destinado para projetos ou

investimentos

A empresa possui planejamento financeiro de curto e longo prazo com metas de crescimento

A motivação dos gestores e funcionários da empresa é alta

Fonte: Dados da pesquisa.

De acordo com os respondentes, as empresas de 3 a 5 anos também têm foco em resultados e buscam as vendas; apesar de apontarem a não existência de conflitos entre administradores e sócios, a certeza quanto a esses itens é bem menor do que nas empresas anteriores. Já os níveis de concordância em relação ao planejamento financeiro de curto e longo prazo e de a motivação dos gestores e funcionários permaneceram constantes.

Houve discordância que o nível de fornecedores insatisfeitos é alto e que os gestores são realistas e têm medo de mudanças. Isso sugere empresas estejam na fase de plenitude; no período de maioridade. Não existem conflitos entre funcionários e entre a administração, no entanto, a certeza também diminuiu em relação às empresas mais jovens. $\mathrm{O}$ nível de dificuldades para se obter crédito junto aos bancos não é grande, e as empresas possuem percentual de lucros destinados a projetos e investimentos. Essas características são típicas de empresas em fase de estabilidade no período de envelhecimento.

$\mathrm{O}$ fato de existir uma divisão entre essas características pode significar que as empresas de 3 à 5 anos estão em fase de transição, da plenitude para a estabilidade,
3,40

3,00

3,00

Infância
Neutro
Neutro
Plenitude
Neutro
Estabilidade
Burocracia e Morte
Estabilidade
Neutro
Plenitude
Estabilidade
Plenitude
Plenitude
Estabilidade
Plenitude
Plenitude

ou do período de maioridade para o período de envelhecimento. Castro Silva, Jesus e Melo (2010) salientam que as empresas podem evidenciar ao mesmo tempo, tanto aspectos atinentes à longevidade, quanto à mortalidade. De acordo com Oliveira et al. (2012) há relação entre a estrutura funcional e o CVO. Beuren, Rangel e Hein (2012) mencionam que apesar de existir proximidade entre alguns estágios, não há uma estrutura explícita entre eles. Dessa maneira, em meio aos estágios de envelhecimento, a renovação tanto da estrutura, quanto do sistema social da empresa pode elevar a expectativa de vida do negócio.

A Tabela 7 expõe as características do grupo de empresas com mais de 5 anos e mostra uma grande quantidade de características da fase de plenitude. Das 25 empresas com mais de 5 anos, a maioria têm mais de 10 funcionários e faturam acima de $\mathrm{R} \$ 240.000,00$ anuais, e em relação a gerência o resultado foi bem dividido, sendo 10 administradas unicamente pelo proprietário, 11 pelo proprietário e um administrador profissional e 4 somente por um administrador profissional.

Tabela 7 - Características e Ranking Médio de Empresas acima de 5 anos 
Análise conjunta do ciclo de vida e da longevidade empresarial: um enfoque em indústria, comércio e agronegócio

\begin{tabular}{|c|c|c|}
\hline Característica & $\begin{array}{l}\text { Ranking } \\
\text { Médio }\end{array}$ & Fase do CVO \\
\hline A empresa possui diretrizes normas e regras a serem seguidas pelos funcionários & 4,00 & Adolescência \\
\hline $\begin{array}{l}\text { O enfoque principal da empresa é a produção de resultados, ou seja, a busca pelas } \\
\text { vendas }\end{array}$ & 3,96 & Plenitude \\
\hline A administração é centralizada no proprietário & 3,36 & Infância \\
\hline O ambiente é informal com poucas reuniões de pessoal e pouquíssima hierarquia & 2,64 & Plenitude \\
\hline O nível de reclamações de clientes é alto & 2,92 & Plenitude \\
\hline O nível de fornecedores insatisfeitos é alto & 2,44 & Plenitude \\
\hline O nível de funcionários improdutivos é alto & 2,60 & Plenitude \\
\hline O nível de dificuldades em obter crédito junto aos bancos é alto & 2,72 & Estabilidade \\
\hline A empresa não possui problemas de fluxo de caixa & 3,16 & Estabilidade \\
\hline O nível de vendas está aumentando rapidamente & 3,88 & Plenitude \\
\hline $\begin{array}{l}\text { A empresa não tem planejamento de vendas e assume compromissos superiores da } \\
\text { produção }\end{array}$ & 2,24 & Plenitude \\
\hline Não existem conflitos entre administradores e sócios & 3,56 & Plenitude \\
\hline Não existem conflitos entre funcionários & 3,36 & Estabilidade \\
\hline O nível de verbas destinadas para marketing e pesquisa é alto & 3,48 & Plenitude \\
\hline Os gestores possuem os pés no chão, tem medo de mudanças & 2,68 & Plenitude \\
\hline $\begin{array}{l}\text { A empresa possui algum percentual do lucro destinado para projetos ou } \\
\text { investimentos }\end{array}$ & 3,20 & Plenitude \\
\hline $\begin{array}{l}\text { A empresa possui planejamento financeiro de curto e longo prazo com metas de } \\
\text { crescimento } \\
\text { A motivacão dos gestores e funcionários da empresa é alta }\end{array}$ & $\begin{array}{l}3,88 \\
3,86\end{array}$ & $\begin{array}{l}\text { Plenitude } \\
\text { Plenitude }\end{array}$ \\
\hline
\end{tabular}

Fonte: Dados da pesquisa.

Diferente dos outros grupos de empresas analisados detectou-se a concordância que a administração é centralizada no proprietário com um nível de escore menor, ou seja, cada vez mais a gestão profissional tem reduzido esse aspecto pertencente à fase infância. As empresas possuem regras e normas a serem seguidas pelos funcionários, característica da fase adolescente, mas, sendo essas duas as únicas características do período de crescimento.

Ainda, essas empresas não possuem problemas de fluxo de caixa e não existem conflitos entre funcionários, características que sinalizam para a fase de estabilidade, assim como o fato de não concordarem que suas empresas têm dificuldades em conseguir crédito junto aos bancos.

Os respondentes discordaram que $\mathrm{o}$ ambiente das empresas é informal e com pouca hierarquia. Discordam também que o nível de reclamação de clientes seja alto, que o nível de fornecedores insatisfeito seja elevado, e o nível de funcionários improdutivos seja alto. As empresas não têm planejamento de vendas comprometendo a produção, e os gestores são conservadores. A partir dessas características da fase de plenitude pode-se afirmar que as empresas com mais de cinco anos estão no período de maioridade. As empresas podem correr o risco de ficar presa nas últimas fases caso não consiga renovar. Mas, isso pode acontecer apenas em empresas em que os gestores tenham medo de mudanças.

Após a análise que procurou identificar as fases do CVO em que se encontravam as empresas pesquisadas, partiu-se para uma análise comparativa a fim de identificar quais as práticas de gestão que são adotadas por essas empresas, e que foram identificadas como práticas utilizadas por empresas longevas, segundo Martins e Pereira (2009). O resultado dessa análise está exposto no Quadro 3.

\begin{tabular}{|c|c|c|c|c|c|}
\hline \multirow{2}{*}{ Ordem } & Prática de Gestão & Até 2 anos & De 2 a 3 anos & De 3 a 5 anos & $\begin{array}{c}\text { Acima de 5 } \\
\text { anos }\end{array}$ \\
\hline $1^{\circ}$ & Conhecimento do Mercado & 0 & $\mathrm{X}$ & 0 & $\mathrm{X}$ \\
$2^{\text {o }}$ & Liderança & $\mathrm{X}$ & $\mathrm{X}$ & $\mathrm{X}$ & $\mathrm{X}$ \\
$2^{\text {o }}$ & Inovação Constante & $\mathrm{X}$ & 0 & $\mathrm{X}$ & $\mathrm{X}$ \\
$3^{\text {o }}$ & Valorização das Pessoas & $\mathrm{X}$ & $\mathrm{X}$ & $\mathrm{X}$ & $\mathrm{X}$
\end{tabular}




\begin{tabular}{|c|c|c|c|c|c|}
\hline $3^{\circ}$ & Cultura Arraigada & $\mathrm{X}$ & $X$ & $\mathrm{X}$ & $\mathrm{X}$ \\
\hline $4^{\circ}$ & Controle Financeiro & $\mathrm{X}$ & $X$ & $\mathrm{X}$ & $\mathrm{X}$ \\
\hline $4^{\circ}$ & Estratégia Clara e Definida & $\mathrm{X}$ & $\mathrm{X}$ & $\mathrm{X}$ & $\mathrm{X}$ \\
\hline $4^{\circ}$ & Metas Claras & $\mathrm{X}$ & $X$ & 0 & $\mathrm{X}$ \\
\hline $4^{\circ}$ & Foco na Tecnologia & $\mathrm{X}$ & $\mathrm{X}$ & $\mathrm{X}$ & $\mathrm{X}$ \\
\hline $5^{\circ}$ & Foco no Crescimento e Desempenho & $\mathrm{X}$ & $\mathrm{X}$ & $\mathrm{X}$ & $\mathrm{X}$ \\
\hline $6^{\circ}$ & Parcerias & $\mathrm{X}$ & $\mathrm{X}$ & $\mathrm{X}$ & $\mathrm{X}$ \\
\hline $6^{\circ}$ & Processo Decisório & $\mathrm{X}$ & $\mathrm{X}$ & 0 & $\mathrm{X}$ \\
\hline $7^{\circ}$ & Crescimento não Planejado & 0 & 0 & 0 & 0 \\
\hline $7^{\circ}$ & Hierarquia Gerencial & $\mathrm{X}$ & $X$ & 0 & $\mathrm{X}$ \\
\hline $7^{\circ}$ & Investimentos & 0 & 0 & 0 & $\mathrm{X}$ \\
\hline $7^{\circ}$ & Senso de Comunidade & $\mathrm{X}$ & $\mathrm{X}$ & $X$ & $\mathrm{X}$ \\
\hline
\end{tabular}

Fonte: Compilado de Martins e Pereira (2009) e dos dados desta pesquisa.

As empresas com até 2 anos apresentaram a maioria das práticas utilizadas pelas empresas longevas, porém, deixaram de apresentar a primeira prática no Ranking de Martins e Pereira (2009), que é o conhecimento de mercado, além de não apresentarem a prática de investimentos e de crescimento não planejado. Já as empresas de 2 à 3 anos relataram o conhecimento de mercado e deixaram de apresentar, além do crescimento não planejado e da prática de investimento, a prática de inovação constante. Por fim, nas empresas de 3 à 5 anos visualizou-se o menor número de práticas de empresas longevas, não indicando conhecimento de mercado, a primeira no Ranking, metas explícitas, processo decisório, crescimento não planejado, hierarquia gerencial e investimentos. Frohlich, Rosseto e Silva (2007) assinalam que as práticas de gestão adequadas repercutem positivamente no $\mathrm{CVO}$, acarretando sua longevidade. Ainda, contribui a existência do empreendedorismo (OLIVEIRA; CASTRO SILVA; ARAÚJO, 2012) e da mentoria

empresarial (COSTA; DIAS, 2011). Em geral, as práticas implantadas pelas empresas são similares, mas divergentes ao preconizado pela teoria (MARTINS; PEREIRA, 2009).

O resultado das empresas com mais de 5 anos sugeriu uma grande similaridade com as empresas longevas dado que apenas uma prática não foi constatada, sendo, o crescimento não planejado. É importante que o planejamento de longo prazo seja realizado aliado à necessidade do subsistema social, estrutura e interação com o ambiente. Aliás, todos concordaram sob a sua existência, seja na empresa mais jovem, ou na mais longeva.

\section{Conclusão}

O objetivo deste trabalho foi identificar em que fase do CVO situam-se as empresas industriais, comerciais e do agronegócio de Patrocínio/MG, com base na perspectiva teórica de Adizes (1990), e quais as práticas de gestão das empresas longevas, enunciadas por Martins e Pereira (2009), essas empresas têm adotado. Isso foi desenvolvido pesquisando-se empresas participantes da ACIP do município de Patrocínio/MG.

Identificaram-se os seguintes aspectos das empresas parte da ACIP: a maioria atua no comércio, no agronegócio e na indústria, nessa ordem; comercializam roupas, calçados, artigos esportivos, móveis para residências e escritórios, equipamentos de informática, combustíveis e lubrificantes, materiais para construção, gêneros alimentícios, artigos de papelaria; produzem móveis e esquadrias metálicas; e comercializam defensivos agrícolas e peças para tratores e implementos agrícolas.

As empresas que têm até 2 anos, em maior parte, são gerenciadas pelos proprietários e situam-se nas fases adolescência e plenitude. Naquelas com 2 
Análise conjunta do ciclo de vida e da longevidade empresarial: um enfoque em indústria, comércio e agronegócio

à 3 anos, a metade é gerenciada pelo sócio, o restante conta, também, com um gestor profissional, e se encontram na fase de plenitude, com aspectos da fase de estabilidade, sinalizando uma possível transição para a fase de envelhecimento. Das empresas que tem de 3 à 5 anos, a quase totalidade é gerenciada só pelo proprietário, apresentaram características das fases de maioridade e de envelhecimento, e ao que parece, estão na mesma fase de transição das empresas de 2-3 anos. Já as empresas com mais de 5 anos indicaram elementos da fase de plenitude, algumas contrataram gestores profissionais, e possuem características das fases de infância, adolescência e de crescimento.

Quanto às práticas de gestão conectadas à longevidade, as empresas com até 2 anos revelaram a maioria delas, contudo, parece inexistir o conhecimento de mercado, a prática de investimentos e ocorrer o crescimento sem planejamento. As empresas de 2 à 3 anos não sinalizaram o crescimento planejado, a prática de investimento e a de inovação constante. Já nas empresas de 3 à 5 anos, indicaram o menor número de práticas de empresas longevas. Enquanto isso, as empresas com mais de 5 anos sinalizaram aderência as características das empresas longevas, já que apenas a prática do crescimento planejado não foi detectada.

Alguns fatores que tem influenciado de forma positiva no desempenho organizacional, CVO e longevidade são as estratégias geradoras de vantagem no mercado incluem os custos de transação, incentivos financeiros e remuneração dos empregados, investimento nos ambientes da organização, medidas mercadológicas eficazes, configuração da CG, estrutura funcional, comportamento empreendedor, a mentoria e as práticas de gestão. Conquanto isso ser presente nos vários estágios, interligados e que guardam semelhanças, a literatura empírica ainda não capturou uma lógica total efetiva acerca dos seus entrelaça- mentos .

Por fim, foi possível concluir que, independente da idade, a amostra possui, em maior quantidade, características da fase de plenitude, seguida de estabilidade, e poucas na infância e adolescência. Isso indica que, as empresas de Patrocínio/MG estão, em maior parte, no período de maioridade, com uma possível transição para o período de envelhecimento, como sugere a teoria de Adizes (1990). Naquelas com mais de 5 anos (empresas mais maduras), essa provável fase de transição foi percebida em uma intensidade menor e já existe uma relação mais próxima do equilíbrio entre as características da plenitude. Outra diferenciação foi obtida quando se procedeu à análise comparativa das práticas de gestão, o que sinalizou que esse grupo está aplicando quase todas as práticas, como preconizado pela teoria, distinto de Martins e Pereira (2009), que verificaram diferença entre a teoria e os dados empíricos (MARTINS; PEREIRA, 2009). Hipoteticamente, pode-se construir um cenário em que as empresas com até 5 anos, que estão adentrando em uma fase de transição para o envelhecimento e, ainda, não adotam algumas práticas, evoluam para a condição daquelas acima de 5 anos já mais consolidadas no período de crescimento e utilizam mais as práticas. Seus gestores precisam dar maior atenção a essa questão, haja vista que, as práticas gerenciais permitem maior solidificação de mercado, e incremento na longevidade empresarial.

Como contribuição acadêmica desta pesquisa, a teoria de Adizes indicouse suficiente para aplicação e obtenção de um melhor entendimento acerca dessas MPE's, podendo, então, ser implementada por seus pares, e, além disso, mostrou-se adequada para ser aplicada conjuntamente com os pressupostos teóricos de Martins e Pereira (2009). Além disso, forneceu subsídios para o aperfeiçoamento dos processos de gestão dessas empresas, a partir do conhecimento das fases em que se situam e das práticas de gestão adotadas. 
Isso permite vislumbrar ações necessárias e que a teoria indica como efetivas para o sucesso e longevidade dos empreendimentos, ampliando sua produção de riquezas.

No que tange às limitações ocorridas para a consecução desta pesquisa, aponta-se a indisponibilidade de vários empresários em responder ao questionário, o que reduziu o volume de dados obtidos, bem como seu poder de generalização. Entretanto, não invalida as análises. Recomenda-se a extensão dessa pesquisa para outros setores, a partir do que, podem-se desenvolver análises comparativas, além de aplicar outras abordagens de $\mathrm{CVO}$ e de longevidade.

\section{Referências}

ADIZES, I. Os ciclos de vida das organizações: como e por que as empresas crescem e morrem e o que fazer a respeito. São Paulo: Pioneira, 1990.

ANDRADE, D. M.; LIMA, J. B.; PIERNI, V. L.; TAVARES, T. S. Ciclo de vida, competição e estratégias em pequenas e microempresas. Revista Eletrônica de Administração, v. 10, n. 39, mai./jun. 2004.

BATTILANA, A. N.; BERALDO, V. Aplicação do conceito de ciclo de vida organizacional na definição e determinação das fases de uma organização varejista. Revista Brasileira de Gestão de Negócios, v. 15, p. 15-26, ago., 2004.

BEUREN, I. M.; RENGEL, S.; HEIN, N. Ciclo de vida organizacional pautado no modelo de Lester, Parnell e Carraher (2003) e na lógica fuzzy: classificação de empresas de um segmento industrial de Santa Catarina. Revista de Administração da USP, v. 47, n. 2, p. 197-216, 2012.

BURGELMAN, R. A.; GROVE, A. S. Let chaos reign, then rein in chaos repeatedly: managing strategic dynamics for corporate longevity. Strategic Mana- gement Journal, v. 28, p. 965-979, 2007.

CALDAS, M.; FACHIN, R.; FISCHER, T. (org). Handbook de estudos organizacionais: modelos de análises e novas questões em estudos organizacionais. São Paulo: Atlas, 1998.

CARVALHO, K. L.; SARAIVA JÚNIOR, A. F.; FREZATTI, F.; COSTA, R. P. A contribuição das teorias do ciclo de vida organizacional para a pesquisa em contabilidade gerencial. Revista de Administração da Mackenzie, v. 11, n. 4, jul./ago. 2010.

CASTRO SILVA, W. A.; JESUS, D.; MELO, A. Ciclo de vida das organizações: sinais de longevidade e mortalidade de micro e pequenas indústrias na região de Contagem/MG. Revista de Gestão, v. 17, n. 3, p. 245-263, jul./set. 2010.

CHURCHILL, N.; LEWIS, V. The five stages of small business growth. Harvard Business Review, May/June, 1983.

COLliS, J.; HUSSEY, R. Pesquisa em administração: um guia prático para alunos de graduação e pós-graduação. 2 . ed. trad. Porto Alegre: Bookman, 2005.

COSTA, S. S. F.; DIAS, S. M. R. C. O papel da mentoria na longevidade de empresas familiares: o caso "Ferreira Costa". In: ENANPAD, 35., 2011, Rio de Janeiro (RJ). Anais... Rio de Janeiro: ANPAD, 2011.

DEGEN, R. J. O Empreendedor: fundamentos da iniciativa empresarial. São Paulo: McGraw Hill, 1989.

DEPARTAMENTO INTERSINDICAL DE ESTATÍSTICA E ESTUDOS SOCIOECONÔMICOS (DIEESE). Anuário do trabalho na MPE 2008. São Paulo: DIEESE, 2008. Disponível em: http://die ese.org.br/anu/anuarioTrabalhoSebrae2008 .pdf.

DIBRELL, C.; CRAIG, J.; HANSEN, E. Natural environment, market orientation, and firm innovativeness: an organizational 
Análise conjunta do ciclo de vida e da longevidade empresarial: um enfoque em indústria, comércio e agronegócio

life cycle perspective. Journal of Small Business Management, v. 49, n. 3, p. 467489, 2011.

DICKINSON, V. Cash flow patterns as a proxy for firm life cycle. The Accounting Review, v. 86, n. 6, p. 1969-1994, 2011.

DOLABELA, F. Oficina do empreendedor. São Paulo: Cultura Editores Associados, 1999.

DUTRA, I. S.; PREVIDELLI, J. J. Fatores condicionantes da mortalidade de empresas: um estudo dos empreendedores de micro e pequenas empresas paranaenses. Revista Capital Científico, v. 3, p. 29-50, jan./dez., 2005.

ENGELEN, A.; BRETTEL, M.; HEINEMANN, F. The antecedents and consequences of a market orientation: the moderating role of organizational life cycles. Journal of Marketing Management, v. 26, n. 5-6, p. 515-517, May, 2010 .

FERREIRA, C. C. Fatores de administração que interferem na longevidade de organizações do setor de móveis da região metropolitana de Curitiba-PR. Dissertação (Mestrado em Administração) - Programa de Pós-Graduação em Administração. UFRGS: Rio Grande do Sul, 2001.

FLECK. D. Archetypes of organizational success and failure proceeding of the 2005 . Academy of Management Annual Meeting. Honolulu, Hawaii, Ago. 2005.

FREITAS, A. A. F.; COSTA, F. J.; BARROSO, H. C. M. P. Ciclo de vida organizacional: um estudo no setor de supermercados. In: EnANPAD, 26., 2002, Salvador/BA. Anais... Rio de Janeiro: ANPAD, 2002.

FROHLICH, L.; ROSSETO, R.; SILVA, A. Implicações das práticas de gestão no ciclo de vida organizacional. Revista Análise, v. 18, n. 1, p. 139-160, jan./jun. 2007.
GREINER, L. Evolution and revolution as organizations grow. Harvard Business Review, v. 50, p. 37-46, Jul./Ago. 1972.

HAIR, J.; BLACK, W.; BABIN, J.; ANDERSON, R.; TATHAM, R. Análise multivariada de dados. 6. ed. Porto Alegre: Bookman, 2009.

JONES, G. R. Organizational theory: text and cases. New Jersey: Prentice Hall, 2000 .

JUNQUEIRA, E.; FELLOUS, S.; FREZATTI, F.; NASCIMENTO, A. Ciclo de vida das organizações: análise epistemológica e uma proposta de 5 estágios. In: EnANPAD, 32., 2008, Rio de Janeiro/RJ. Anais... Rio de Janeiro: ANPAD, 2008.

KATZ, D.; KAHN, R. L. Psicologia social das organizações. 2. ed. São Paulo: Atlas, 1976.

LIAO, C. N. Incentive reward control: based on the competitive advantage, transaction cost economics and organizational life cycle viewpoint. Human Systems Management, v. 27, p. 123-130, 2008.

LIKERT, R. Novos padrões de administração. 2. ed. São Paulo: Pioneira, 1979.

LUCENA, E. A. Administração estratégica nos diferentes estágios do modelo do ciclo de vida organizacional. In.: ENEGEP, 23., 2003, Ouro Preto/MG. Anais... Rio de Janeiro: ABEPRO, 2003.

MACHADO-DA-SILVA, C.; VIEIRA, M.; DELLAGNELO, E. Ciclo de vida, controle e tecnologia: um modelo para análise das organizações. Organizações e Sociedade, v. 5, n. 11, jan./abr. 1998.

MADHANI, P. M. Optimal compensation: rebalancing pay. Journal of Indian Management, p. 31-42, Apr./Jun. 2012.

MARTINS, G. J. T.; PEREIRA, M. F. Longevidade Organizacional: estudo em três organizações do setor têxtil de Santa Catarina. In.: SEMEAD, 12., 2009, São Paulo/SP. Anais... São Paulo: USP, 2009. 
MAUAD, T. M.; MARTINELLI, D. Ciclo de vida setorial: uma proposta para orientar o desenvolvimento local e as políticas públicas. In: EnANPAD, 29., 2005, Brasília/DF. Anais... Rio de Janeiro: ANPAD, 2005.

MAYFIELD, M.; MAYFIELD, J.; STEPHENS, D. The relationship of generic strategy typing and organizational longevity: a preliminary analysis in the comic book industry using the Miles and Snow typology. Competitive Review: An International Business Journal, v. 17, 2007.

MINTZBERG, H. Power and organization life cycles. Academy of Management Review, v. 9, p. 207-224, 1984.

MORGAN, G. Images of organization. Califórnia: Sage Publications, 1986.

OLIVEIRA, L. H. Exemplo de cálculo de ranking médio para likert. Notas de Aula. Metodologia científica e técnicas de pesquisa. Mestrado/PPGA/FACECA: Varginha, 2005.

OLIVEIRA, J. R. C.; CASTRO SILVA, W. A.; ARAÚJO, E. A. T. Longevidade empresarial e características empreendedoras: análise das MPE s da microrregião de Teófilo Otoni/MG. In: Tourism and Management Studies, 2012, Algarve. Anais... Portugal: ESGHT, 2012.

OLIVEIRA, M. L. G.; CASTRO SILVA, W. A.; ARAÚJO, E. A. T.; SILVA, M. S. Aderência entre a estrutura funcional de empresas de contabilidade e o ciclo de vida organizacional e longevidade na perspectiva de Miller e Friesen. In: Tourism and Management Studies, 2012, Algarve. Anais... Portugal: ESGHT, 2012.

QUINN, R; CAMERON, K. Organizational life cycles and shifting criteria of affectiveness. Management Science, New York, v. 29, p. 33-51, Jan. 1983.
SCOTT, M.; BRUCE, R. Five stages of growth in small business. Long Range Planning, v. 20, n. 3, 1987.

SELLTIZ, C.; WRIGHTSMAN, L.; COOK, S. Métodos de pesquisa nas relações sociais. 2. ed. São Paulo: EPU, 1987.

SERVIÇO DE APOIO ÀS MICRO E PEQUENAS EMPRESAS (SEBRAEMG). Dados de Pesquisa 2004. Disponível em: <http: www.sebrae mg.com.br >. Acesso: 08 ago. 2011.

SOUZA, B. C.; NECYK, J. A.; FREZATTI, F. Ciclo de vida das organizações e a contabilidade gerencial. Revista UEM, v. 27, n. 1, p. 9-22, jan./abr., 2008. 